\title{
Corosolic acid impairs human lung adenocarcinoma A549 cells proliferation by inhibiting cell migration
}

\author{
BIAO LI, YONGJIE LI, QIONGYU WANG, FAN LI and FU LI \\ Department of Thoracic Surgery, The Second Affiliated Hospital of Hainan Medical University, Haikou, \\ Hainan 570311, P.R. China
}

Received April 5, 2018; Accepted January 15, 2019

DOI: $10.3892 / \mathrm{ol} .2019 .10262$

\begin{abstract}
The present study aimed to investigate the anticancer effects of corosolic acid (CA) in the human lung adenocarcinoma A549 cell line. A549 cells were treated with increasing concentrations of CA, prior to assessing cell viability, migration rate, vascular endothelial growth factor receptor 2 (VEGFR2) kinase activity and cytoskeleton structure. In addition, in vivo imaging system was used to analyze the anticancer effects of CA in vivo. Results demonstrated that CA exhibited a low cytotoxicity with a half maximal inhibitory concentration of $65 \mu \mathrm{M}$. In addition, $4 \mu \mathrm{M}$ CA efficiently inhibited A549 cell migration. Furthermore, CA inhibited VEGFR2 kinase activity and disrupted tubulin structure. Data also revealed that CA inhibited A549 cell proliferation in a xenograft mouse model. In conclusion, results from the present study suggested that CA may be used as a novel potential therapy for lung cancer.
\end{abstract}

\section{Introduction}

Lung cancer is the most prevalent type of cancer worldwide, and $\sim 80-85 \%$ of this malignancy comprises the non-small cell lung cancer (NSCLC) (1). NSCLC is an aggressive type of tumor with a 5-year survival rate of $16 \%$. Although NSCLC diagnosis is made at an early stage, and despite the availability of numerous treatments, including surgery, radiation or adjuvant chemotherapy, $\sim 50 \%$ of patients with NSCLC relapse (2). The development of novel efficient therapeutic alternatives for NSCLC is therefore crucial.

Cell migration is a key step in tumor development and metastasis (3). Novel therapies that could inhibit cell migration have therefore been considered as novel approaches for lung cancer treatment. Previous studies have revealed

Correspondence to: Professor Biao Li, Department of Thoracic Surgery, The Second Affiliated Hospital of Hainan Medical University, 48 Baishuitang Road, Haikou, Hainan 570311, P.R. China E-mail: libiao701@163.com

Key words: lung cancer, corosolic acid, vascular endothelial growth factor receptor 2 , cytoskeleton structure, in vivo imaging system that vascular endothelial growth factor receptor (VEGFR) signaling pathway, particularly VEGFR2, serves crucial role in regulating cancer cell migration $(4,5)$. Furthermore, it has been reported that phosphorylated VEGFR2 activates downstream Ras homologous (Rho)-GTP hydrolase (GTPase), induces cytoskeleton filaments remodeling and subsequently activates tumor cell migration (6,7). In addition, $\mathrm{Ku}$ et al (8) demonstrated that VEGFR knockdown reduces hepatocellular carcinoma migration. These findings suggest that VEGFR2 pathway serves an important role in tumor cell migration.

Numerous plant-derived bioactive compounds, including xylocoside $\mathrm{G}$, formononetin and camptothecin, have been isolated from traditional plants and are widely used to treat cancers (9-11). The tripernoid corosolic acid (CA), also known as $2 \alpha$-hydroxyursolic acid, is present in numerous plants, including Lagerstroemia speciosa L. and Actinidia chinensis, and has exhibited anticancer ability against various types of tumor. For example, CA induces apoptosis in multiple cell types through different pathways as follows: CA induces apoptosis of the cervix adenocarcinoma HeLa and osteosarcoma MG-63 cell lines via mitochondrial signaling pathway; CA induces apoptosis of the stomach carcinoma SNU-601 cell line through adenosine monophosphate-activated protein kinase activation; and $\mathrm{CA}$ induces apoptosis of the stomach carcinoma NCI-N87 cell line via human epidermal growth factor receptor 2-downregulated cell cycle arrest (12-14). However, the anticancer effects of CA and its underlying mechanisms remain poorly understood in lung cancer.

In the present study, CA exhibited a weak toxicity in A549 cells, and decreased A549 cell migration. Results also demonstrated that CA significantly inhibited VEGFR2 kinase activity, and downregulated VEGFR2/Ras-related C3 botulinum toxin substrate 1 (Racl) binding ability. Data from mice xenograft demonstrated that $\mathrm{CA}$ administration inhibited tumor growth in vivo. Taken altogether, these results suggested that CA may be considered as a potential novel therapy for NSCLC, and requires therefore further investigation.

\section{Materials and methods}

Cell line and reagents. The A549 cell line was purchased from National Infrastructure of Cell Line Resource (Beijing, China) 
and maintained in high-glucose Dulbecco's modified Eagle's medium (DMEM) supplemented with $10 \%$ fetal bovine serum (FBS; both Gibco; Thermo Fisher Scientific, Inc., Waltham, MA, USA). Cells were placed at $37^{\circ} \mathrm{C}$ in a humidified atmosphere containing 5\% $\mathrm{CO}_{2}$. CA, MTT, tyrphostin-SU 1498 (cat. no. SU 1498), Tween-20, protease inhibitor cocktail (cat. no. P8340) and dimethyl sulfoxide (DMSO) were obtained from Sigma-Aldrich (Merck KGaA, Darmstadt, Germany). Recombinant Protein G-Sepharose 4B beads were purchased from Thermo Fisher Scientific Inc. The rabbit primary antibodies against GAPDH (cat. no. 2118; 1:5,000), VEGFR2 (cat. no. 2479; 1:2,000) and phosphorylated (p)-VEGFR2 (Tyr1059; cat. no. $3817 ; 1: 1,000)$ were purchased from Cell Signaling Technology (Cell Signaling Technology Europe, B.V., Leiden, The Netherlands). Rabbit antibody against phosphoserine (P-Ser; cat. no. ab9332; 1:5,000) was purchased from Abcam (Cambridge, UK). Horseradish peroxidase (HRP)-conjugated goat anti-rabbit $\operatorname{IgG}$ secondary antibody (1:3,000, cat. no. A-21109) was obtained from Invitrogen (Thermo Fisher Scientific, Inc.).

Cytotoxicity assay. MTT assay was employed to study CA toxicity on A549 cells as described previously $(8,15,16)$. Briefly, A549 cells were cultured in 96-well plate at the density of $5 \times 10^{3}$ cells/well and treated with $0.1 \%$ DMSO (control) or increasing concentrations of CA $(20,40,60,80$ and $100 \mu \mathrm{M}$, CA diluted in DMSO) for $48 \mathrm{~h}$. $(8,16)$ A total of $20 \mu \mathrm{l}$ MTT $(5 \mathrm{mg} / \mathrm{ml})$ was then added to cells for $6 \mathrm{~h}$. Formazan crystals were dissolved with SDS and absorbance was read on a microplate reader [590/650 $\mathrm{nm}$ (absorbance/reference) wavelengths].

Transwell migration assay. To determine cell migration rate, a Transwell assay was employed (8 $\mu \mathrm{m}$ pore; cat. no. 351184; Corning Inc., Corning, NY, USA). Briefly, A549 cells were serum-starved overnight and resuspended in $300 \mu \mathrm{l}$ serum-free DMEM medium containing 0.1\% DMSO (control) or increasing concentrations of CA $(0,1,2,4$ and $8 \mu \mathrm{M})$. Each sample contained $5 \times 10^{4}$ cells, which were cultured in the Transwell upper chamber. The lower chamber was filled with DMEM supplemented with 10\% FBS. Following $16 \mathrm{~h}$ incubation, the lower chamber was isolated and cells were fixed using $4 \%$ paraformaldehyde at room temperature (RT) for $5 \mathrm{~min}$. Cells were then stained with crystal violet. Results represented the mean of counting in three different areas under light microscope (magnification, $\mathrm{x} 40$ ), according to a previous study (17).

Western blotting and co-immunoprecipitation (IP). For western blotting, A549 cells or mouse tumor tissues was lysed in radioimmunoprecipitation assay buffer $(25 \mathrm{mM}$ Hepes, $150 \mathrm{mM} \mathrm{NaCl}, 10 \mathrm{mM} \mathrm{MgCl}{ }_{2}, 1 \%$ Nonidet P-40 and $10 \mathrm{mM}$ DTT) and supplemented with protease inhibitor cocktail (Sigma-Aldrich; Merck KGaA). The protein amount in each sample was determined using NanoDrop 2000 (Thermo Fisher Scientific, Inc.) and a total of $50 \mu \mathrm{g}$ protein/lane was separated via SDS-PAGE on a $10 \%$ gel. The proteins were subsequently transferred onto $0.45 \mu \mathrm{m}$ polyvinylidene difluoride membrane (Thermo Fisher Scientific, Inc.) under $400 \mathrm{~mA}$ current for $1 \mathrm{~h}$. The membrane was blocked with
$5 \%$ non-fat milk powder at RT for $1 \mathrm{~h}$. The membranes were then incubated with primary antibodies against VEGFR2 and p-VEGFR2 (Tyr1059) at $4^{\circ} \mathrm{C}$ over night. After incubation with HRP-conjugated goat anti-rabbit IgG secondary antibody at RT for $1 \mathrm{~h}$, proteins were detected with Immobilon Western Chemiluminescent HRP Substrate (ECL) reagent (cat no. WBKLS0500; EMD Millipore) in a dark room with Kodak film and semi-quantified using ImageJ (release number 1.50i; National Institutes of Health).

For co-IP, A549 cells were treated for $24 \mathrm{~h}$ with $0.1 \%$ DMSO or increasing concentrations of CA $(0,4$ and $8 \mu \mathrm{M})$. An additional well of untreated cells was used as beads only control (control). Cells were then lysed in reduced RIPA buffer [25 mM Hepes, $150 \mathrm{mM} \mathrm{NaCl}, 10 \mathrm{mM} \mathrm{MgCl}$, $1 \%$ Nonidet P-40 and protease inhibitor cocktail (Sigma-Aldrich; Merck $\mathrm{KGaA})]$ and centrifuged at $7,500 \mathrm{x}$ for $10 \mathrm{~min}$ at $4^{\circ} \mathrm{C}$. Supernatant was collected and protein concentration was determined by NanoDrop 2000. A total of $1 \mathrm{mg}$ protein each group was incubated with anti-VEGFR2-immobilized beads (1:100) (for experimental groups) or without primary antibody (for control group) overnight at $4^{\circ} \mathrm{C}$. A quantity of $5 \%$ samples from each group was collected as input. Samples were incubated with PureProteome magnetic beads (cat. no. LSK MAGA10, EMD Millipore Billerica) for $1 \mathrm{~h}$ at $4^{\circ} \mathrm{C}$ and washed three times with PBS containing 5\% Tween-20 at $4^{\circ} \mathrm{C}$. Beads were collected with magnetic rock after each washing step and boiled at $95^{\circ} \mathrm{C}$ for $5 \mathrm{~min}$. Samples were eventually detected by western blotting as aforementioned. P-Ser primary antibody was used for IP groups while VEGFR2 and GAPDH were used for input. Membranes were incubated with primary antibodies overnight at $4^{\circ} \mathrm{C}$, and with HRP-conjugated goat anti-rabbit IgG secondary antibody for $2 \mathrm{~h}$ at room temperature. Protein amount was determined as described above.

Kinase activity assay. Kinase activity assay was performed with the ADP-Glo ${ }^{\mathrm{TM}}$ kinase assay kit (Promega Corporation, Madison, WI, USA). Increasing concentrations of CA were diluted with kinase reaction buffer and added to tubes containing $3 \mathrm{ng}$ of kinase insert domain receptor (KDR; also known as VEGFR2) for $10 \mathrm{~min}$. Then, $0.1 \mu \mathrm{g} / \mu \mathrm{l}$ enzyme substrate and $10 \mu \mathrm{M}$ ATP were added to each tube for $1 \mathrm{~h}$. ADP-Glo reagent $(25 \mu \mathrm{l})$ was then added to each tube for $40 \mathrm{~min}$ at room temperature. Eventually, $50 \mu \mathrm{l}$ kinase detection buffer was added to each tube. All samples were transferred onto a 96-well plate and results were read with a microplate reader.

Rho-GTPase activity assay. A549 cells were treated with $0.1 \%$ DMSO (control) or CA for $24 \mathrm{~h}$ and lysed with RIPA buffer. Tumor tissues from mouse model was collected and lysed in RIPA buffer. Cell lysates $(500 \mu \mathrm{g})$ or tissue lysates (1 mg) were incubated with purified glutathione-S-transferase (GST) fusion protein conjugated with Racl binding domain (PAK-PBD; Cytoskeleton, Inc., Denver, CO, USA) at $4^{\circ} \mathrm{C}$ overnight. MagneGST ${ }^{\text {TM }}$ beads (Promega Corporation) were added to each sample for further protein pull down. Pull down samples were centrifuged at $12,000 \mathrm{x} \mathrm{g}$ for $30 \mathrm{~min}$ at $4^{\circ} \mathrm{C}$ and detected by western blotting as previously described. 
Labeling of mitochondria and tubulin. A549 cells were cultured in $35 \mathrm{~mm}$ plastic dishes and treated with $0.1 \%$ DMSO (control) or CA for $48 \mathrm{~h}$. Cells were treated with Tubulin Tracker $^{\mathrm{TM}}$ and MitoTracker ${ }^{\circledR}$ (Invitrogen, both diluted 1:1,000 as final concentration) for $5 \mathrm{~min}$ at $37^{\circ} \mathrm{C}$. Live cells were directly observed under confocal microscope (magnification, $\mathrm{x} 60$ ).

Animal xenograft model and in vivo imaging system (IVIS) Spectrum Imaging. Animal experiments were performed under approved protocol of the Institutional Animal Care and Use Committee of The Hainan Medical University. The male NOD/SCID mice (4-6 weeks old; $n=60$ ) were purchased from the Chinese Academy of Sciences, Beijing, China and taken care of in the Laboratory Animal Center of Hainan Medical University. They were kept into individually-ventilated cages, and allowed free access to food and water. A549 cells $\left(2 \times 10^{6}\right)$ were labeled with D-luciferin potassium by Sinochrome (Shanghai, China; cat. no. BC-219-10) and suspended in $200 \mu \mathrm{l}$ DMEM to reach the final density of $1 \times 10^{7}$ cells $/ \mathrm{ml}$. This cell suspension was eventually injected subcutaneously into the flanks of each mouse. Two weeks later, a total of 30 out of the 60 mice successfully grew tumor cells. These mice subsequently received intraperitoneal (i.p.) daily injection of $50 \mu 110 \%$ DMSO (control) (8) or various concentrations of CA (2, 4 or $8 \mathrm{mg} / \mathrm{kg} /$ day) for 14 days. Each group consisted of $6,8,8$ and 8 mice, respectively. Tumor size was directly visualized by IVIS spectrum imaging system (PerkinElmer, Inc., Waltham, MA, USA) and fluorescence intensity was calculated.

Statistical analysis. Statistical analysis was conducted with GraphPad Prism (version no. 4.0; GraphPad Software, Inc.). All data were expressed as the means \pm standard errors and calculated from at least three independent experiments. Statistical comparisons were assessed by using Student's t-test or one-way analysis of variance followed by a post hoc analysis (Tukey test) when applicable. $\mathrm{P}<0.05$ was considered to indicate a statistically significant difference.

\section{Results}

CA significantly inhibits cells migration. To determine the antitumor effects of $\mathrm{CA}$ in vitro, the effect of $\mathrm{CA}$ on cell viability and migration were assessed. A549 cells were treated with control (DMSO) or increasing concentrations of CA $(0-100 \mu \mathrm{g} / \mathrm{ml})$ for $48 \mathrm{~h}$ prior to measuring cell viability with MTT assay. As shown in Fig. 1A, CA decreased A549 cell viability in a dose-dependent manner, and the half maximal inhibitory concentration $\left(\mathrm{IC}_{50}\right.$ ) was $65 \mu \mathrm{M}$. Transwell assay was performed to measure A549 cell migration following treatment with CA. Results demonstrated that CA inhibited A549 cell migration in a dose-dependent manner, and $\mathrm{IC}_{50}$ for migration was $4 \mu \mathrm{M}$ (Fig. $1 \mathrm{~B}$ and $\mathrm{C}$ ). These results indicated that CA inhibited more effectively A549 cell migration than $\mathrm{A} 549$ cell viability with a ratio $\mathrm{IC}_{50}$ cytotoxicity/ $\mathrm{IC}_{50}$ migration $=16$.

CA inhibits VEGFR2 kinase activity. A previous study has reported that VEGF/VEGFR signaling pathway may be involved in cancer cell migration, and that VEGFR inhibition could reduce hepatocellular carcinoma cell migration (8). To determine whether VEGFR was involved in A549 cell migration, VEGFR pathway activity was assessed following A549 cell treatment with CA. Results from co-IP and western blotting experiments indicated that CA significantly reduced VEGFR2 phosphorylation. In addition, determination of VEGFR2 kinase activity demonstrated that $1.95 \mu \mathrm{M} \mathrm{CA}$ inhibited VEGFR2 activity by $50 \%$ (Fig. 2C). To further confirm whether VEGFR2 is involved in A549 cell migration, cell treatment with the VEGFR2 specific inhibitor SU1498 $(50 \mu \mathrm{M})$ demonstrated that VEGFR2 inhibition may efficiently reduce A549 cell migration (Fig. 2D).

CA inhibits Racl activity and disrupts tubulin organization. Small GTPase activation is an important downstream event following VEGFR activation. The present study investigated whetherCA treatment could induce downstream Rho-GTP activation in A549 cells. Results demonstrated that CA decreased VEGFR2 phosphorylation at Tyr1059 (Fig. 3A and B), which is considered as an important phosphorylation site that elevates downstream Rho-GTPase activity (18). Rho-GTP family activity was further investigated, and results revealed that GTP-bounded-Rac1, but not RhoA or cdc42 (data not shown) was significantly downregulated following CA treatment (Fig. 3C and D). Since small GTPases have crucial roles on cell skeleton rearrangement and physiological organization (19), cell staining with Tubulin Tracker ${ }^{\mathrm{TM}}$ and Mitotracker ${ }^{\circledR}$ was performed prior to analysis with confocal microscopy. Images demonstrated that A549 cell treatment with CA induced tubulin network and mitochondria distribution disruptions (Fig. 3E).

CA exhibits antitumor effect in xenograft in vivo model by regulating Racl activity. A xenograft mouse model was designed to investigate the effect of CA in vivo. Pre-labeled A549 cells were injected in mice and tumor growth was allowed for two weeks. Preliminary data indicated that $\mathrm{mg}$ amount of CA could have an antitumor effect in vivo (data not shown). Following A459 cell injection, mice were treated with various concentrations of CA $(0,2,4$ and $8 \mathrm{mg} / \mathrm{kg} /$ day $)$ daily (i.p. injection) for two weeks. IVIS live imaging was employed daily to monitor tumor growth. Results indicated that 14 days of CA treatment effectively inhibited A549 cell tumor growth in NOD/SCID mice (Fig. 4A-C). Eventually, mice were sacrificed and Racl activity in tumor tissues was measured. In accordance with the in vitro results, CA-treated mice exhibited a decrease in GTP-Rac1 protein level (Fig. 4D and E). These results suggested that CA mechanisms of action may be similar in vitro and in vivo.

\section{Discussion}

VEGF signaling pathway regulates cell migration, proliferation and angiogenesis (20). VEGFR2 is a major receptor in VEGF pathway. VEGFR2-associated signal transduction pathway is initialized by VEGF/VEGFR2 binding, which can lead to VEGFR2 trans-autophosphorylation on its intracellular tyrosine residues (21). Two residues in the VEGFR2 active loop domain were identified as Tyr1054 and Tyr1059, 

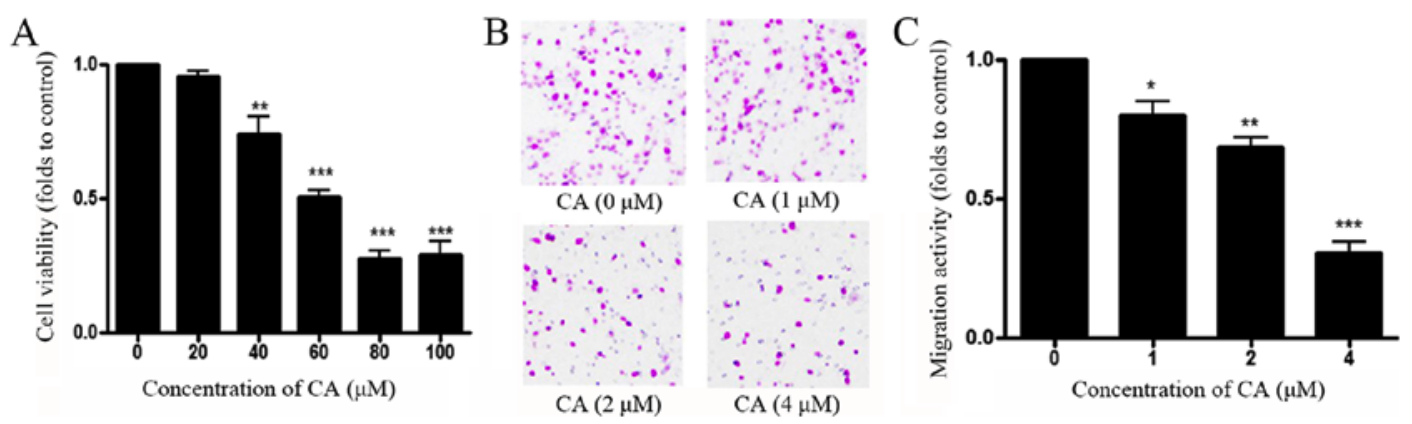

Figure 1. CA treatment reduces cell viability and cell migration of A549 cells. (A) A549 cell were treated with DMSO or indicated concentrations of CA for $48 \mathrm{~h}$ prior to measuring cell viability using MTT assay. (B) Representative images of A549 cell migration assessed with Transwell assay. A549 cells were treated with DMSO or various concentrations of CA for $48 \mathrm{~h}$ and cell migration was assessed by microscopy. (C) Quantification of Transwell assay. $\mathrm{n}=4$. ${ }^{*} \mathrm{P}<0.05,{ }^{* * *} \mathrm{P}<0.01$ and ${ }^{* * *} \mathrm{P}<0.001$, compared with the $0 \mu \mathrm{M}$ group. $\mathrm{CA}$, corosolic acid.
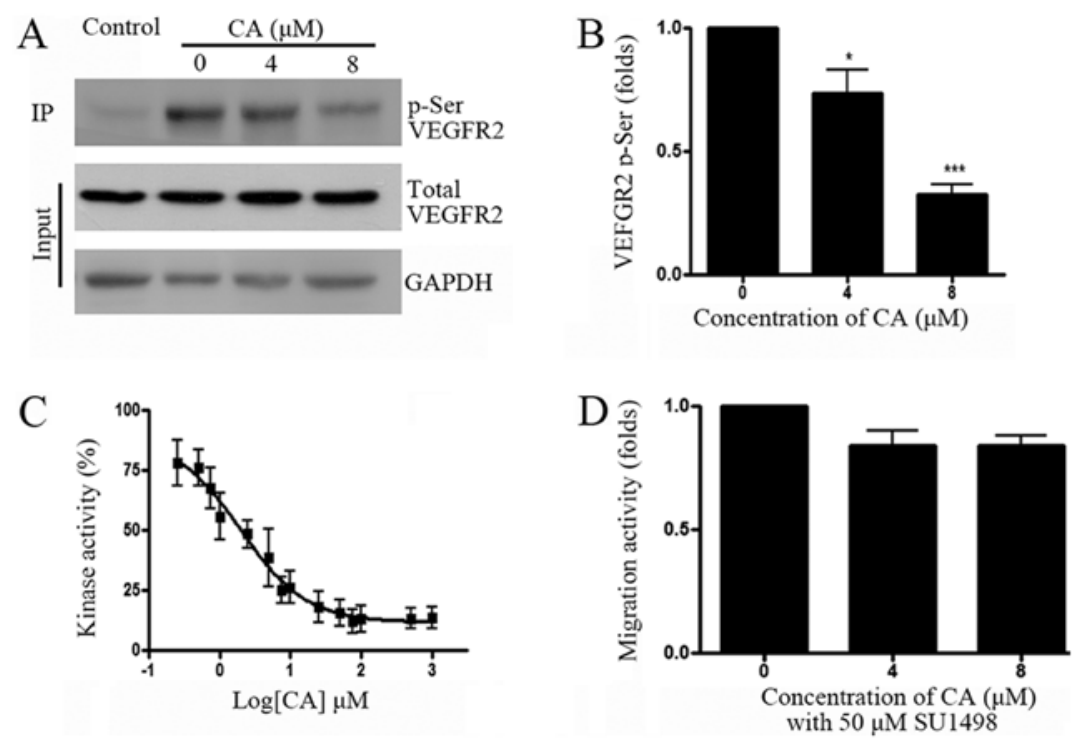

Figure 2. CA inhibits VEGFR2 kinase activity. (A) A549 cells were treated with beads only (control) or increasing concentrations of CA $(0,4$ and $8 \mu \mathrm{M})$ for $24 \mathrm{~h}$, prior to co-IP with anti-VEGFR2 antibody, and subsequent western blotting with anti-phospho-Serine antibody. Total VEGFR2 and GAPDH were detected in lysates (Input). (B) Quantification of phosphor-VEGFR2 level shown in (A), normalized by total VEGFR2. (C) CA effects on VEGFR2 kinase activity measured by ADP-Glo ${ }^{\mathrm{TM}}$ kinase assay ( $\mathrm{n}=4$; kinase activity data were normalized to the control group and the results are shown as percentages). (D) A549 cell were treated with SU1498 for $24 \mathrm{~h}$ and with indicated concentrations of CA for another $24 \mathrm{~h}$. Cell migration ability was measured by Transwell assay. $\mathrm{n}=4$. ${ }^{*} \mathrm{P}<0.05$ and ${ }^{* * *} \mathrm{P}<0.001$, compared with the $0 \mu \mathrm{M}$ group. CA, corosolic acid; VEGRF2, vascular endothelial growth factor receptor 2; IP, immunoprecipitation.

of which phosphorylation is critical for VEGFR2 kinase activity (22). Tyr1054 and Tyr1059 phosphorylation can induce downstream signal transduction, including p21-activated kinase (PAK) activation and cytoskeleton remodeling (23). The present study demonstrated that CA treatment reduced Tyr1059 phosphorylation level of VEGFR2, and VEGFR2 activity. These results may have highlighted a potential mechanism of action for the antimigratory effects of CA in A549 cells.

A previous study reported that VEGF-associated cell migration is dependent of Rac1 activation, and that VEGFR-2 inhibition reduces Rac1 activation (24). Furthermore, VEGFR2 autophosphorylation is critical for VEGFR2-Rac1 pathway activation (25). In the present study, VEGFR2 phosphorylation level in A549 cell was significantly reduced following CA treatment with CA. In addition, the combined treatment of A549 cells with CA and SU1498 did not enhance p-VEGFR2 decrease compared with CA or SU1498 alone, which suggested that CA may reduce cell migration through VEGFR2 phosphorylation.

Rho-GTPase activation and subsequent cytoskeleton rearrangement represent crucial steps for cell migration. For example, Rac1 regulation induces microtubules rearrangement (26). With regards to the migration stage, Rac1 is located at the leading edge of a migrating cell and regulates actin and microtubule reorganization (27). As previously reported, the constitutively active form of Rac1 (Q61L) promotes pioneer behavior in most microtubules, whereas the dominant-negative form of Rac1 (T17N) eliminates these pioneer microtubules (28). In the present study, CA cell treatment significantly reduced GTP-Rac1 expression, a finding that has been previously reported (29). Considering microtubules are one of the key cytoskeleton components (30) and closely regulated mitochondrial distribution $(31,32)$, the disrupted mitochondrial distribution would be a result of microtubule abnormal organization and could reflect cytoskeleton 
A

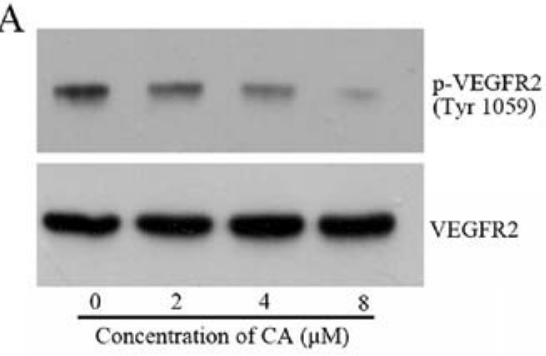

$\mathrm{E}$

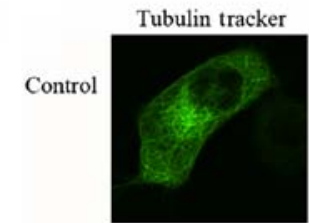

CA
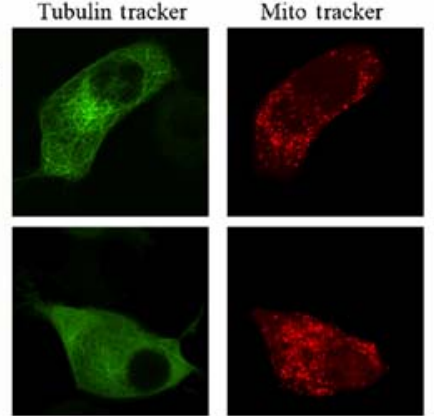

B

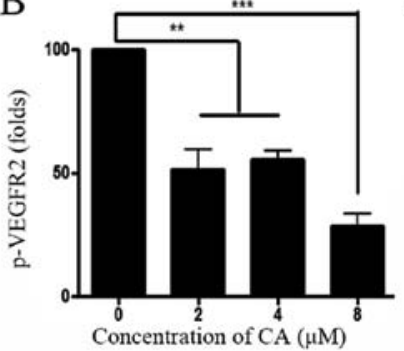

C Control CA $(8 \mu \mathrm{M})$

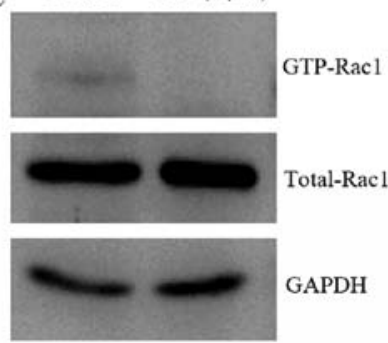

$\mathrm{D}$

Merge
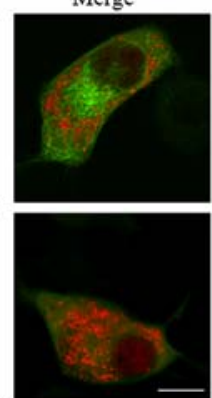

Figure 3. CA inhibits VEGFR2-associated signaling pathway and disrupts cytoskeleton rearrangement. (A) A549 cells were treated with DMSO (control) or indicated concentration of CA for $24 \mathrm{~h}$, prior to assessing VEGFR2 phosphorylation level (Tyr1059) by western blotting. (B) Quantification of WB bands shown in (A). (C) A549 cells were treated with control or indicated concentration of CA for $24 \mathrm{~h}$, prior to assessing Rac1-GTPase by glutathione-S-transferase pull-down and subsequent western blotting. (D) Quantification of phosphor-VEGFR2 level (Tyr 1059) shown in (C), normalized by total VEGFR2. $\mathrm{n}=4$. ${ }^{* *} \mathrm{P}<0.01$ and ${ }^{* * *} \mathrm{P}<0.001$ compared with the $0 \mu \mathrm{M}$ group. (E) A549 cell were treated with DMSO or CA for $24 \mathrm{~h}$ and live cells were stained with Tubulin Tracker $^{\mathrm{TM}}$ and Mitotracker ${ }^{\circledR}$ for $5 \mathrm{~min}$. Cells were immediately observed by confocal microscopy (magnification, x60; scale bar, $10 \mu \mathrm{m}$ ). CA, corosolic acid; Rac1, Ras-related C3 botulinum toxin substrate 1; VEGRF2, vascular endothelial growth factor receptor 2; p, phosphorylated.

A
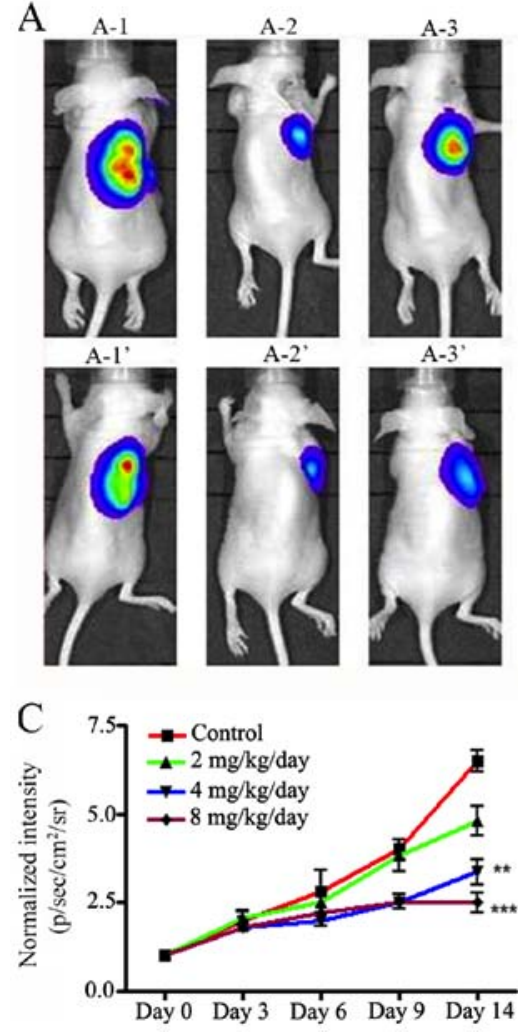
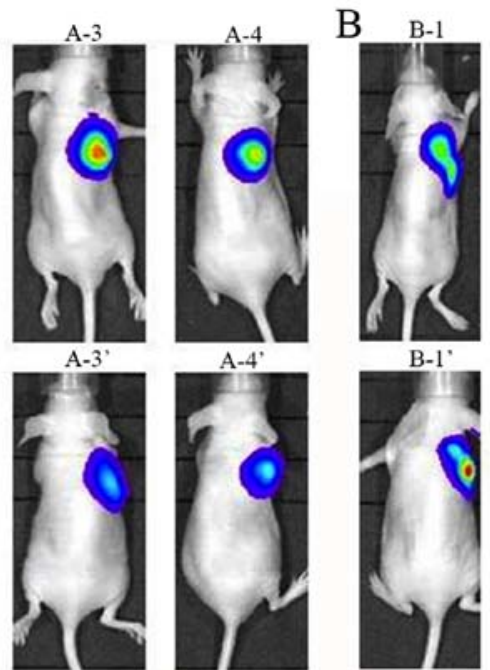

B-1

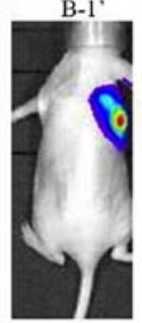

D Control

$\mathrm{CA}(8 \mu \mathrm{M})$

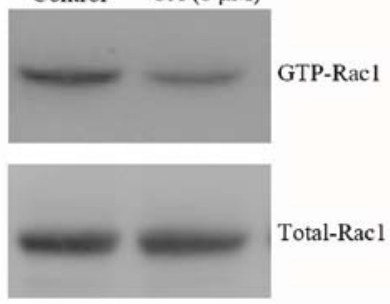

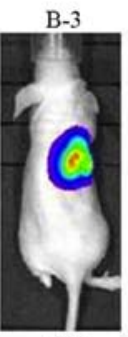

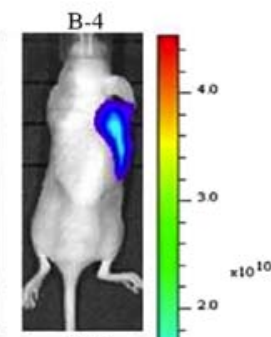

B-2'
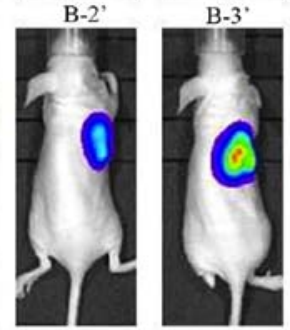

B-4,
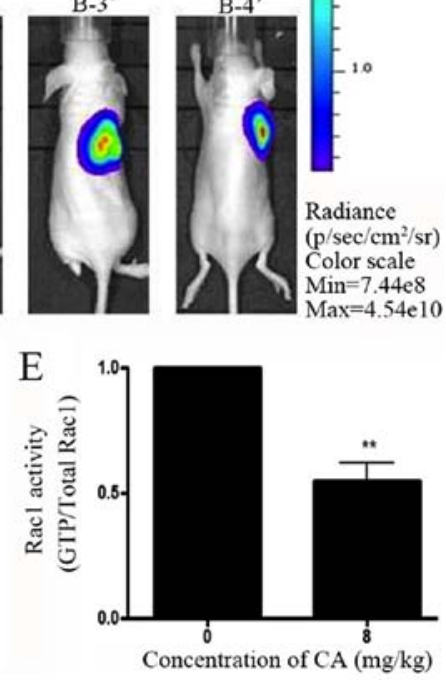

Figure 4. CA exhibits antitumor growth effects in vivo. A549 cells $\left(2 \times 10^{6}\right)$ were subcutaneously injected into the right flanks of NOD/SCID mice (n=60). After two weeks, 30 mice which developed tumors were randomly assigned into several groups and were treated with various concentration of $\mathrm{CA}(0,2,4$ or $8 \mathrm{mg} / \mathrm{kg} / \mathrm{day})$ for 14 days (intraperitoneal injection). (A) A-1-A-4: IVIS imaging results from 4 representative mice prior to CA injection in treatment group. A-1'-A-4': IVIS imaging of the same mice following 14 days treatment with CA. (B) B-1-B-4: IVIS imaging results from 4 representative mice prior to DMSO injection in control group. B-1'-B-4': IVIS imaging of the same mice following 14 days treatment with DMSO treatment. (C) Quantification of IVIS fluorescence intensity. $\mathrm{n}=6$. * $\mathrm{P}<0.05$, ${ }^{* * *} \mathrm{P}<0.01,{ }^{* * *} \mathrm{P}<0.001$ vs. control group. After IVIS observation, mice were sacrificed and tumor tissues were collected to evaluate Rac1 activity. (D) Rac1-GTPase activity was measured by glutathione-S-transferase pull-down and subsequently western blotting. (E) Quantification of GTP-Rac1 level shown in (D), normalized by total Rac1. $\mathrm{n}=3$. $^{* *} \mathrm{P}<0.01$ vs. the $0 \mu \mathrm{M}$ control group $(0 \mu \mathrm{M})$. CA, corosolic acid; Rac1, Ras-related C3 botulinum toxin substrate 1 . 
structure disruption. The current study further tested whether microtubule structure was disrupted by $\mathrm{CA}$ treatment. CA treatment could reduce tubulin density and as a consequence, the mitochondrial distribution changed from arranged along cytoplasmic microtubules (33) to scattered in the perinuclear space. This result indicated CA treatment may disrupt tubulin distribution and organization. Since CA inhibits hepatocellular carcinoma cell migration via inhibition of the VEGFR2-FAK pathway and downstream actin rearrangement (8), data from the present study strongly suggests that CA may inhibit lung cancer A549 cell migration through cytoskeleton disruption.

The present study has a number of limitations. Due to the lack of information regarding the effect of $\mathrm{CA}$ in vivo, lower concentrations of CA were tested in mice in order to minimize a potential cytotoxicity effect. Preliminary data supported that low concentration of CA may exhibit antitumor effects in vivo (data not shown). However, due to the resolution limit of the IVIS system, we can only use a moderate CA concentration $(\mathrm{mg} / \mathrm{kg})$ to show a difference here. It is important to further verify whether concentrations lower than $1 \mathrm{mg} / \mathrm{kg}$ exhibits a similar effect. Eventually, although no changes in the body weight or daily activities of the mice were observed following treatment with a high dose of CA $(8 \mathrm{mg} / \mathrm{kg} / \mathrm{day})$, it could not be excluded that CA may have an effect on the behavior of the mice. Behavioral tests could be employed to confirm the safety of $\mathrm{CA}$ in clinical use.

In conclusion, results from the present study demonstrated that CA treatment exhibited a potential anticancer activity in the A549 cell line and in in vivo. Particularly, CA reduced the migration rate of A549 cells, inhibited VEGFR2 kinase activity, disrupted tubulin remodeling and reduced tumor growth in vivo. In addition, CA exhibited its most potent anticancer effects in the micromolar concentration range. In conclusion, the present study suggests that CA may be considered as a potential chemotherapeutic agent for lung cancer therapy.

\section{Acknowledgements}

Not applicable.

\section{Funding}

No funding was received.

\section{Availability of data and materials}

The datasets used and/or analyzed during the current study are available from the corresponding author on reasonable request.

\section{Authors' contributions}

BL designed the experiment and wrote the manuscript. YL and QW performed the experiments and collected the data. $\mathrm{FaL}$ and FuL analyzed the data and made the figures.

\section{Ethics approval and consent to participate}

Animal experiments were performed under approved protocol of the Institutional Animal Care and Use Committee of The Hainan Medical University.

\section{Patient consent for publication}

Not applicable.

\section{Competing interests}

The authors declare that they have no competing interests.

\section{References}

1. Jemal A, Siegel R, Xu J and Ward E: Cancer statistics, 2010. CA Cancer J Clin 60: 277-300, 2010

2. Jaffe N: Osteosarcoma: Review of the past, impact on the future. The American experience. Cancer Treat Res 152: 239-262, 2009.

3. Smeland S, Bruland OS, Hjorth L, Brosjö O, Bjerkehagen B, Osterlundh G, Jakobson A, Hall KS, Monge OR, Björk O and Alvegaard TA: Results of the scandinavian sarcoma group XIV protocol for classical osteosarcoma: 63 patients with a minimum follow-up of 4 years. Acta Orthop 82: 211-216, 2011.

4. Martin R, Carvalho-Tavares J, Ibeas E, Hernández M, Ruiz-Gutierrez V and Nieto ML: Acidic triterpenes compromise growth and survival of astrocytoma cell lines by regulating reactive oxygen species accumulation. Cancer Res 67: 3741-3751, 2007.

5. Reyes-Zurita FJ, Rufino-Palomares EE, Lupiáñez JA and Cascante M: Maslinic acid, a natural triterpene from Olea europaea L., induces apoptosis in HT29 human colon-cancer cells via the mitochondrial apoptotic pathway. Cancer Lett 273: 44-54, 2009.

6. Claesson-Welsh L and Welsh M: VEGFA and tumour angiogenesis. J Intern Med 273: 114-127, 2013.

7. Lamalice L, Houle F and Huot J: Phosphorylation of Tyr1214 within VEGFR-2 triggers the recruitment of Nck and activation of Fyn leading to SAPK2/p38 activation and endothelial cell migration in response to VEGF. J Biol Chem 281: 34009-34020, 2006 ,

8. Ku CY, Wang YR, Lin HY, Lu SC and Lin JY: Corosolic acid inhibits hepatocellular carcinoma cell migration by targeting the VEGFR2/Src/FAK pathway. PLoS One 10: e0126725, 2015.

9. Prydz K, Vuong TT and Kolset SO: Glycosaminoglycan secretion in xyloside treated polarized human colon carcinoma Caco-2 cells. Glycoconj J 26: 1117-1124, 2009.

10. Li T, Zhao X, Mo Z, Huang W, Yan H, Lin Z and Ye Y: Formononetin promotes cell cycle arrest via downregulation of Akt/Cyclin D1/CDK4 in human prostate cancer cells. Cell Physiol Biochem 34: 1351-1358, 2014.

11. Jeansonne DP, Koh GY, Zhang F, Kirk-Ballard H, Wolff L, Liu D, Eilertsen K and Liu Z: Paclitaxel-induced apoptosis is blocked by camptothecin in human breast and pancreatic cancer cells. Oncol Rep 25: 1473-1480, 2011.

12. Lee MS, Lee CM, Cha EY, Thuong PT, Bae K, Song IS, Noh SM and Sul JY: Activation of AMP-activated protein kinase on human gastric cancer cells by apoptosis induced by corosolic acid isolated from Weigela subsessilis. Phytother Res 24: 1857-1861, 2010.

13. Cai X, Zhang H, Tong D, Tan Z, Han D, Ji F and Hu W: Corosolic acid triggers mitochondria and caspase-dependent apoptotic cell death in osteosarcoma MG-63 cells. Phytother Res 25: 1354-1361, 2011.

14. Horlad H, Fujiwara Y, Takemura K, Ohnishi K, Ikeda T, Tsukamoto $H$, Mizuta $H$, Nishimura $Y$, Takeya $M$ and Komohara Y: Corosolic acid impairs tumor development and lung metastasis by inhibiting the immunosuppressive activity of myeloid-derived suppressor cells. Mol Nutr Food Res 57: 1046-1054, 2013

15. Yu Y, Zhou L, Sun M, Zhou T, Zhong K, Wang H, Liu Y, Liu X, $\mathrm{Xiao} \mathrm{R}, \mathrm{Ge} \mathrm{J}$, et al: Xylocoside $\mathrm{G}$ reduces amyloid- $\beta$ induced neurotoxicity by inhibiting NF- $\mathrm{B}$ signaling pathway in neuronal cells. J Alzheimers Dis 30: 263-275, 2012.

16. Lee HS, Park JB, Lee MS, Cha EY, Kim JY and Sul JY: Corosolic acid enhances 5-fluorouracil-induced apoptosis against SNU-620 human gastric carcinoma cells by inhibition of mammalian target of rapamycin. Mol Med Rep 12: 4782-4788, 2015.

17. Sun $M$ and Zhang $H$ : Par3 and aPKC regulate BACE1 endosome-to-TGN trafficking through PACS1. Neurobiol Aging 60: 129-140, 2017. 
18. Chen TT, Luque A, Lee S, Anderson SM, Segura T and Iruela-Arispe ML: Anchorage of VEGF to the extracellular matrix conveys differential signaling responses to endothelial cells. J Cell Biol 188: 595-609, 2010.

19. Wang H, Sun M, Yang H, Tian X, Tong Y, Zhou T, Zhang T, Fu Y, Guo X, Fan D, et al: Hypoxia-inducible factor- $1 \alpha$ mediates up-regulation of neprilysin by histone deacetylase-1 under hypoxia condition in neuroblastoma cells. J Neurochem 131: 4-11, 2014.

20. Garrett TA, Van Buul JD and Burridge K: VEGF-induced Rac1 activation in endothelial cells is regulated by the guanine nucleotide exchange factor Vav2. Exp Cell Res 313: 3285-3297, 2007.

21. Vazgiourakis VM, Zervou MI, Eliopoulos E, Sharma S, Sidiropoulos P, Franek BS, Myrthianou E, Melissourgaki M, Niewold TB, Boumpas DT and Goulielmos GN: Implication of VEGFR2 in systemic lupus erythematosus: A combined genetic and structural biological approach. Clin Exp Rheumatol 31: 97-102, 2013.

22. Roskoski R Jr: VEGF receptor protein-tyrosine kinases: Structure and regulation. Biochem Biophys Res Commun 375 287-291, 2008

23. Takahashi T, Yamaguchi S, Chida K and Shibuya M: A single autophosphorylation site on KDR/Flk-1 is essential for VEGF-A-dependent activation of PLC-gamma and DNA synthesis in vascular endothelial cells. EMBO J 20: 2768-2778, 2001.

24. Meissner M, Michailidou D, Stein M, Hrgovic I, Kaufmann R and Gille J: Inhibition of Rac1 GTPase downregulates vascular endothelial growth factor receptor-2 expression by suppressing Sp1-dependent DNA binding in human endothelial cells. Exp Dermatol 18: 863-869, 2009.
25. Clegg LW and Mac Gabhann F: Site-specific phosphorylation of VEGFR2 is mediated by receptor trafficking: Insights from a computational model. PLoS Comput Biol 11: e1004158, 2015.

26. Singleton PA, Dudek SM, Chiang ET and Garcia JG: Regulation of sphingosine 1-phosphate-induced endothelial cytoskeletal rearrangement and barrier enhancement by S1P1 receptor, PI3 kinase, Tiam1/Rac1, and alpha-actinin. FASEB J 19: 1646-1656, 2005.

27. Wittmann T, Bokoch GM and Waterman-Storer CM: Regulation of leading edge microtubule and actin dynamics downstream of Rac1. J Cell Biol 161: 845-851, 2003.

28. Shin OH and Exton JH: Differential binding of arfaptin 2/POR1 to ADP-ribosylation factors and Rac1. Biochem Biophys Res Commun 285: 1267-1273, 2001.

29. Li XQ, Tian W, Liu XX, Zhang K, Huo JC, Liu WJ, Li P, Xiao X, Zhao MG and Cao W: Corosolic acid inhibits the proliferation of glomerular mesangial cells and protects against diabetic renal damage. Sci Rep 6: 26854, 2016.

30. Liang P and MacRae TH: Molecular chaperones and the cytoskeleton. J Cell Sci 110: 1431-1440, 1997.

31. Frederick RL and Shaw JM: Moving mitochondria: Establishing distribution of an essential organelle. Traffic 8: 1668-1675, 2007.

32. Woods LC, Berbusse GW and Naylor K: Microtubules are essential for mitochondrial dynamics-fission, fusion, and motility-in dictyostelium discoideum. Front Cell Dev Biol 4: 19, 2016.

33. Heggeness MH, Simon M and Singer SJ: Association of mitochondria with microtubules in cultured cells. Proc Natl Acad Sci USA 75: 3863-3866, 1978. 